\title{
Help-seeking and receipt of treatment among UK service personnel*
}

Amy C. Iversen, Lauren van Staden, Jamie Hacker Hughes, Tess Browne, Neil Greenberg, Matthew Hotopf, Roberto J. Rona, Simon Wessely, Graham Thornicroft and Nicola T. Fear

\section{Background}

For armed forces personnel, data on help-seeking behaviour and receipt of treatment for mental disorders are important for both research and policy.

\author{
Aims \\ To examine mental healthcare service use and receipt of \\ treatment in a sample of the UK military.
}

\section{Method}

Participants were drawn from an existing UK military health cohort. The sample was stratified by reserve status and by participation in the main war-fighting period of the Iraq War. Participants completed a telephone-based structured diagnostic interview comprising the Patient Health Questionnaire and Primary Care Post-Traumatic Stress Disorder Screen (PC-PTSD), and a series of questions about service utilisation and treatment receipt.

\section{Results}

Only $23 \%$ of those with common mental disorders and still serving in the military were receiving any form of medical professional help. Non-medical sources of help such as chaplains were more widely used. Among regular personnel in receipt of professional help, most were seen in primary care $(79 \%)$ and the most common treatment was medication or counselling/psychotherapy. Few regular personnel were receiving cognitive-behavioural therapy (CBT). These findings are comparable with those reported for the general population.

\section{Conclusions}

In the UK armed forces, the majority of those with mental disorders are not currently seeking medical help for their symptoms. Further work to understand barriers to care is important and timely given that this is a group at risk of occupational psychiatric injury.

\section{Declaration of interest}

J.H.H. is a Ministry of Defence civil servant seconded to the Academic Centre for Defence Mental Health. N.G. is a fulltime active service medical officer seconded to the Academic Centre for Defence Mental Health. S.W. is Honorary Civilian Consultant Advisor in Psychiatry to the British army.
The ongoing conflicts in Iraq and Afghanistan have caused the death of several hundred members of the UK armed forces. ${ }^{1,2}$ Others have been physically injured, sometimes severely. There is a close relationship between measures of physical and psychological injury in wartime $e^{3}$ so it is inevitable that some who have served in either conflict will return with mental disorders. ${ }^{4-6}$ Post-conflict mental disorders affect not only the individual, but also their families, their commanders who are deprived of skilled trained personnel ${ }^{7}$ and, ultimately, the Chancellor who has to pay the war pension.

It is therefore a research priority to establish not only how many have developed such disorders, but also whether or not they are receiving any treatment, and if so, whether or not that treatment is appropriate. Numerous articles in the media, always based on anecdote, have suggested that treatment is inadequate, either when the person is still in regular military service, a reservist ${ }^{8}$ or after they leave (when they become the responsibility of the National Health Service (NHS)). ${ }^{9}$ However, to date there has been no systematic research to confirm or refute such concerns. In this study we examine mental healthcare service utilisation and receipt of treatment in a large sample of the UK military, which includes reservists and those who have left the service (veterans).

\section{Method}

The method is described in detail elsewhere. ${ }^{10}$ In summary, we conducted a cross-sectional study consisting of a structured interview delivered over the telephone which included diagnostic

*This paper has been corrected in deviation from print and in accordance with a correction printed in the September 2010 issue of the Journal. instruments and details of service utilisation. The sample was drawn from an existing military cohort, stratified by deployment history and regular/reserve status. A two-phase survey technique was used and those who scored $\geqslant 4$ on the 12 -item General Health Questionnaire at the first stage of the cohort study were oversampled.

\section{Participants}

This study was based on a sample drawn from phase 1 of the King's Centre for Military Health Research (KCMHR) military health study. Full details of this study and responders can be found in Hotopf et al. ${ }^{6}$ Phase 1 was the first phase of a cohort study of UK military personnel in service at the time of the 2003 Iraq War. In total 4722 regular and reserve personnel who were deployed on the war-fighting phase of the Iraq War and 5550 regular and reserve personnel who were not deployed to Iraq at this time completed a questionnaire about their military and deployment experiences, lifestyle factors and health outcomes. A proportion of the study participants were subsequently deployed on later Iraq deployments, whose mission was counter-insurgency rather than war fighting.

The participant pool for the current study was drawn from the pool of individuals who returned completed questionnaires from phase 1 of the KCMHR military health study and gave signed consent to be followed up. Those who were likely to have psychiatric problems were identified using the 12-item General Health Questionnaire $(\mathrm{GHQ})^{11}$ data from phase 1. A random sample of those who scored above the threshold for 'GHQ caseness' (score of $\geqslant 4$ ) were selected for interview together with a randomly selected subgroup of the non-GHQ cases. Case 
participants were oversampled; $70 \%$ of the sample were in the GHQ case group, and 30\% were in the non-GHQ case group. Within the case and non-case groups, in order to ensure adequate power to make key statistical inferences, we stratified the sample by regular/reserve status (50\% regular, $50 \%$ reserve), and deployment status (50\% deployed on the main fighting period of the Iraq War (TELIC 1), 50\% deployed elsewhere or not deployed). In all other respects, group participants were representative of the KCMHR military health study responders with regards to service branch and demographic characteristics (age, rank and ethnicity) and in turn the KCMHR military health study was representative of the UK military in 2003 and those who deployed on the main war fighting phase of the Iraq War. ${ }^{6}$ From the 1083 participants who were eligible, we achieved a response rate of $76 \%(n=821)$.

\section{Interview schedule}

The telephone interview schedule included the following sections: deployment experience since 2003; Patient Health Questionnaire $(\mathrm{PHQ})^{12}$ with an additional measure for the diagnosis of posttraumatic stress disorder (PTSD; the 4-item Primary Care PTSD Screen (PC-PTSD)); ${ }^{13}$ perceived needs, health service use (based on a modified version of the Client Services Receipt Inventory), ${ }^{14}$ receipt of treatment, and barriers to care (these will be reported in a separate publication). The only demographic information collected was change in marital status and rank since all other relevant information was collected during phase $1 .^{6}$ All interviews were conducted during 2006-7.

\section{Diagnostic assessment}

We used the Patient Health Questionnaire (PHQ) as a diagnostic instrument to measure the prevalence of common mental disorders, ${ }^{12}$ which has been validated for telephone use. ${ }^{15}$ Standard diagnostic algorithms were used to score the PHQ. For PTSD symptoms, we used a short measure developed for primary care by the National Center for PTSD (PC-PTSD) $)^{13}$ and we used a score of 3 or more to define caseness. The screen is used in the Post Deployment Health Assessment (PDHA $)^{5}$ and Post Deployment Reassessment (PDHRA) mandated by the US Department of Defense. ${ }^{16}$ In order to improve the specificity of the measure, we included a lifetime DSM-IV Criterion A1 event-screening questionnaire taken from the National Comorbidity Study. ${ }^{17}$

\section{Mental health care utilisation}

For those who self-reported an 'emotional, stress-related, alcohol or family problem' (hereafter referred to as a mental health problem), we enquired about their past year's contact with a variety of mental healthcare providers in both primary (general practitioners (GPs) and medical officers) and secondary care (community psychiatric nurses, psychologists and psychiatrists). Comorbidity was common but often unrecognised, and it was not possible to ask about individual diagnoses in turn; instead we opted to ask about service utilisation in relation to the most significant problem as defined by the participant. We also asked about their contact in the past year with non-medical professional service providers (such as social workers, welfare officers and chaplains). Finally, we enquired about informal sources of help (for example partners/spouses, internet searches and friends). For each medical provider, we asked about the number of contacts in the past year and for all other sources of help we invited participants to respond simply 'yes' or 'no'.

\section{Treatment receipt}

For those who reported a mental health problem, we asked whether they had received any treatment in the past year. If they reported receipt of treatment, we then asked whether they had received: psychotherapy or counselling; medication; and/or cognitive-behavioural therapy (CBT). For those who reported taking medication, we asked whether they had taken it as instructed in order to determine adherence. In order to determine the type of talking treatment that participants had received, and specifically to detect whether they had received CBT, interviewers were trained to ask about a series of cue words and phrases that would identify the psychotherapy as CBT (for example, between-session work or homework, agenda setting with the therapist etc).

\section{Analysis}

All statistical analyses were undertaken using the statistical software package STATA (version 10.0 for Windows). The majority of the data reported are descriptive statistics (percentages with their 95\% confidence intervals). To compare service use among regulars, reservists and veterans, odds ratios are presented with 95\% confidence intervals, using regular still-serving personnel as the reference group. Percentages are weighted to take account of the sampling strategy used for this study. For the purposes of this paper, the majority of the analyses reported are based on those that have a diagnosis on the structured clinical interview, and perceived that they had a problem $(n=281)$.

\section{Ethical Issues}

The study received approval from both the King's College Hospital NHS Research Ethics Committee (ref: 05/Q0703/155) and also from the Ministry of Defence (Navy) Personnel Research Ethics Committee (ref: 0522/22).

\section{Results}

\section{Perceived mental health problems}

For those who had a diagnosis identified at interview, we examined individuals' perception that they had a 'stress, emotional, alcohol or family problem'. Three-quarters of regulars with either depressive/anxiety disorders or PTSD perceived that they had a problem, whereas just under half of those with alcohol misuse perceived they had a problem (Table 1). Findings were similar for reservists. Although not significant, veterans were, in general, more likely than regulars and reservists to recognise that they had a diagnosis, with $97 \%$ of veterans with PTSD perceiving they had a mental health problem.

\section{Help-seeking}

Those who perceived they had a mental health problem, were asked about help-seeking (Table 2). Over $80 \%$ of those who perceived they had a problem had sought some type of help. Most help-seekers had made use of informal sources of support such as a spouse or friend, rather than seeking professional help. Only $23 \%$ of those with alcohol problems had sought professional help compared with $50 \%$ of those with depression/anxiety and $64 \%$ of those with PTSD. Rates of informal help-seeking for alcohol were also lower (73\%) than for the other disorders (depression $82 \%$, PTSD 85\%). Regulars did not differ from reservists in terms of help-seeking behaviours. Veterans were less likely to use informal sources of help for depression than regulars, but this difference was no longer significant once confounders were adjusted for (age and deployment status). 


\begin{tabular}{|c|c|c|c|c|c|c|c|c|}
\hline & \multicolumn{2}{|c|}{ Overall $(n=821)$} & \multicolumn{2}{|c|}{ Regulars $(n=301)$} & \multicolumn{2}{|c|}{ Reserves $(n=302)$} & \multicolumn{2}{|c|}{ Veterans $(n=218)$} \\
\hline & Weighted \% & $95 \% \mathrm{Cl}$ & Weighted \% & $95 \% \mathrm{Cl}$ & Weighted \% & $95 \% \mathrm{Cl}$ & Weighted \% & $95 \% \mathrm{Cl}$ \\
\hline Any PHQ diagnosis $(n=325)$ & 56.1 & $43.8-67.7$ & 57.0 & $42.0-70.8$ & 65.5 & $48.6-79.3$ & 69.4 & $47.7-85.0$ \\
\hline Depressive/anxiety disorder $(n=205)$ & 74.5 & $60.9-84.5$ & 75.3 & $51.4-89.8$ & 75.0 & $51.3-89.5$ & 72.9 & $46.9-89.2$ \\
\hline Alcohol misuse $(n=196)$ & 62.2 & $52.3-71.3$ & 46.2 & $29.1-64.2$ & 56.3 & $36.1-74.6$ & 77.5 & 46.5-93.2 \\
\hline PTSD $(n=110)$ & 79.7 & $57.1-92.1$ & 78.0 & 35.9-95.7 & 70.0 & 36.0-90.6 & 97.2 & $90.1-99.2$ \\
\hline
\end{tabular}

\section{Characteristics of help-seekers}

We examined a series of potential demographic associations with help-seeking (further detail available from the authors on request). Univariate analysis showed that for regulars, having no qualifications made it more likely that an individual would seek help. For reservists, females were more likely to seek help. For veterans, being in the Royal Air Force, being medically downgraded and having a diagnosis (on the PHQ or on the PC-PTSD) was associated with help-seeking. There was an association between functional impairment of borderline significance in all groups (test for trend $P=0.003$ ). Of note, still-serving personnel who deployed to Iraq on the main war fighting phase of the war were not more likely to seek help.

\begin{tabular}{|c|c|c|}
\hline & $n$ & $\begin{array}{l}\text { Weighted } \\
\%\end{array}$ \\
\hline \multicolumn{3}{|c|}{ Perceived mental health problem $(n=508)$} \\
\hline Any help & 441 & 82.1 \\
\hline Any professional help & 196 & 31.2 \\
\hline Medical professional help ${ }^{b}$ & 129 & 18.5 \\
\hline Non-medical professional helpc & 108 & 17.5 \\
\hline Any informal help ${ }^{d}$ & 412 & 78.2 \\
\hline \multicolumn{3}{|c|}{$\begin{array}{l}\text { Perceived mental health problem + depressive/ } \\
\text { anxiety disorder }(n=173)\end{array}$} \\
\hline Any help & 156 & 88.5 \\
\hline Any professional help & 85 & 49.9 \\
\hline Medical professional help ${ }^{b}$ & 65 & 30.9 \\
\hline Non-medical professional helpc & 46 & 28.8 \\
\hline Any informal help ${ }^{d}$ & 141 & 82.2 \\
\hline \multicolumn{3}{|c|}{$\begin{array}{l}\text { Perceived mental health problem + alcohol misuse } \\
(\mathrm{n}=147)\end{array}$} \\
\hline Any help & 130 & 79.0 \\
\hline Any professional help & 58 & 23.2 \\
\hline Medical professional help ${ }^{b}$ & 38 & 15.6 \\
\hline Non-medical professional helpc & 37 & 14.7 \\
\hline Any informal help ${ }^{d}$ & 120 & 72.6 \\
\hline \multicolumn{3}{|c|}{$\begin{array}{l}\text { Perceived mental health problem + PTSD symptoms } \\
(\mathrm{n}=95)\end{array}$} \\
\hline Any help & 90 & 97.3 \\
\hline Any professional help & 48 & 63.6 \\
\hline Medical professional help ${ }^{b}$ & 34 & 54.3 \\
\hline Non-medical professional helpc & 29 & 26.9 \\
\hline Any informal help ${ }^{d}$ & 83 & 84.6 \\
\hline \multicolumn{3}{|c|}{$\begin{array}{l}\text { PTSD, post-traumatic stress disorder } \\
\text { a. Self-report of any stress, emotional, alcohol-related or family problem. } \\
\text { b. General practitioner, medical officer, counsellor, psychologist, psychotherapist, } \\
\text { psychiatric nurse. } \\
\text { c. Chaplain, vicar, member of faith community, military welfare officer, family officer, } \\
\text { social worker, housing worker, service charity, Citizens' Advice Bureau. } \\
\text { d. Spouse, partner, family member, self-help group, internet searches, websites, } \\
\text { civilian friends, military friends. }\end{array}$} \\
\hline
\end{tabular}

\section{Sources of help}

Among those who perceived they had a mental health problem and were receiving professional help, the most frequently used source of medical professional help was from a GP or medical officer (this varied from $72 \%$ for alcohol misuse to $98 \%$ for depressive/anxiety disorder) (online Table DS1). Because of the small numbers of people who had sought help it was difficult to determine whether there were any real differences in sources of help for regulars, reservists or veterans (data not shown but available from the authors).

\section{Interest in receiving help}

Those who perceived that they had a mental health problem but were not seeking help were asked whether they were interested in receiving help (online Table DS2). Only a small proportion of personnel in this group were interested in receiving help (this varied from $15 \%$ for alcohol misuse to $18 \%$ for PTSD). Veterans were significantly more likely to be interested in receiving help than regulars for depressive/anxiety disorder (adjusted odds ratio $(\mathrm{OR})=2.58,95 \%$ CI 1.45-4.59) and alcohol problems (adjusted $\mathrm{OR}=2.87,95 \%$ CI 1.46-5.64). There was no difference between regulars and reservists in their interest in receiving help for any diagnosis examined, or for regulars and veterans for PTSD symptoms.

\section{Treatment being received}

Of those who perceived that they had a mental health problem, had a diagnosis of depressive/anxiety disorder and were seeking help from medical sources, $76.5 \%$ were receiving treatment (Table 3 ). In total $55.8 \%$ were receiving medication, $50.6 \%$ were receiving counselling/psychotherapy and $3.2 \%$ had received in-patient treatment. For those who had alcohol problems, $84 \%$ were receiving treatment, the majority of which was counselling (47\%), in-patient treatment (25\%) and medication (25\%). There was no difference between regulars, reservists and veterans in the type of treatment being received (data not shown but available from the authors), but numbers receiving treatment within the overall sample are small. Few service personnel with a diagnosis of depressive/anxiety disorder were receiving CBT (12.9\%). The most common medications prescribed were antidepressants $(84 \%)$ and benzodiazepines (11\%). Adherence with medication was $86 \%$ for depression, $40 \%$ for alcohol misuse and $77 \%$ for PTSD. There were no differences between regulars, reservists and veterans in rates of adherence.

\section{Discussion}

\section{Key findings}

Three key finding emerge from this study. The first is that more than three-quarters of those with a diagnosis chose not to access 
Table 3 Proportion of those with perceived mental health problems and seeking help from medical sources (within the past year) by diagnosis

$n$

Weighted $\%$

\begin{tabular}{|lrr|}
\hline Depressive/anxiety disorder ( $\mathrm{n}=65)$ & & \\
Any treatment & 44 & 76.5 \\
Medication & 34 & 55.8 \\
Cognitive-behavioural therapy & 7 & 12.9 \\
Other psychotherapy/counselling & 26 & 50.6 \\
In-patient stay & 1 & 3.2 \\
\hline Alcohol misuse ( $\mathrm{n}=38)$ & & \\
Any treatment & 24 & 84.3 \\
Medication & 16 & 25.3 \\
Cognitive-behavioural therapy & 1 & 6.3 \\
Other psychotherapy/counselling & 14 & 46.8 \\
In-patient stay & 1 & 25.1 \\
\hline Post-traumatic stress disorder symptoms ( $\mathrm{n}=34)$ & & \\
Any treatment & 27 & 74.1 \\
Medication & 19 & 29.2 \\
Cognitive-behavioural therapy & 7 & 6.0 \\
Other psychotherapy/counselling & 16 & 47.4 \\
In-patient stay & 2 & 19.6
\end{tabular}

medical help for their problem, but instead are making use of informal sources of help such as chaplains. This reticence to seek medical help is most evident among those with alcohol problems and depression, compared with those with PTSD. Second, the majority of those with a diagnosis are not receiving treatment. Third, a percentage of interviewees with a diagnosis on structured interview fail to recognise that they suffer from a mental disorder and might benefit from treatment; recognition was lowest for alcohol problems and depression/anxiety and better for PTSD.

\section{Strengths and weaknesses of the study}

To our knowledge, this is the first study to date that has systematically examined service utilisation and treatment receipt in a representative sample of the UK military. The strengths of this study are the relatively large sample and high response rate, with no evidence of bias in terms of health between responders and non-responders. ${ }^{10}$ The sample is diverse, representing all three services, both those who have deployed and those who have not, and includes reservists and those who have left. The study used a structured diagnostic instrument, and did not rely on questionnaire self-report of symptoms or distress. As data collection took place independently of the military, data quality was unlikely to be unaffected by participants' concerns that their problems would have been reported back to the chain of command. Although our response rate was high, our sample was already based on a $61 \%$ response rate. ${ }^{6}$ It is possible that we missed the most vulnerable, unwell or socially excluded members of the still-serving or veteran population such as those in prison or those who are homeless. But importantly, we found no evidence that non-participants were less healthy than participants in the original sample. ${ }^{18}$

We used the PHQ and PC-PTSD instruments to detect common mental disorders, and these measures were chosen for their brevity, acceptability, and validity in military populations. ${ }^{5,19}$ However, like all tests for mental disorders, they have limitations. Many argue that the existing measures in use for common disorders and PTSD are unable to sift out those with mental disorders that result in functional impairment and require treatment. ${ }^{20-22}$ Of relevance to this study, we cannot be sure that the common mental disorders we have detected are disabling and persistent and therefore require treatment, or whether service personnel are in fact making the correct decision not to consult a professional about their symptoms. Even if this were true, a proportion of those scored as cases on our screening measures will include those who are functionally impaired and overall rates of help-seeking and treatment receipt among those with symptoms is low. As a result of the low numbers of help-seekers, we had small numbers when comparing receipt of different services or treatments and thus we may have been underpowered to detect true differences between groups.

We did not obtain objective data on service utilisation, and therefore were unable to ascertain the validity of the self-report methodology we used. Interviewers were carefully trained to probe to ascertain the sort of talking treatment that individuals were receiving; nonetheless, it is possible that some people were receiving CBT but did not identify their treatment as such. Although we relied on self-recall of the past year's service utilisation and treatment receipt, recent studies suggest that this is a relatively accurate method of obtaining information on service use, ${ }^{23}$ particularly if the interviews are conducted in a setting in which confidentiality is preserved. ${ }^{24,25}$ It has been suggested that recall bias may lead to an overestimation of self-report of service use in people who have more distressing disorders. ${ }^{26}$ If this has occurred, our results will have underestimated the extent of unmet need, especially among those with serious disorders.

\section{Recognition of mental disorders}

A substantial proportion of those we diagnosed with common mental disorders, especially those with an alcohol problem, did not acknowledge that they had experienced a stress, emotional or alcohol problem. It has been suggested that 'mental health literacy' is an important first step in the pathway to care. ${ }^{27}$ Subjective perception of a mental disorder has been shown to influence the likelihood of help-seeking and receipt of treatment, especially in primary care. ${ }^{28}$ Poor recognition of mental disorders is not unique to the military; only $39 \%$ of the Australian population were able to recognise depression when described in a vignette, ${ }^{27}$ and men are less likely to recognise mental illness than women. ${ }^{29}$ The physical symptoms of anxiety and depressive disorders are particularly poorly recognised. ${ }^{30,31}$ Mental health literacy is clearly important for the military as they are at increased risk of occupational psychiatric injury. It would be interesting to compare recognition of mental disorders in the military with similar occupational groups such as firefighters or police.

\section{Help-seeking}

In the veteran population we found that objective evidence of poor health (as evidenced by previous medical downgrading and/or the presence of a current diagnosis on the PHQ/PC-PTSD) predicted help-seeking, but we did not demonstrate this for stillserving personnel or reservists. Subjective functional impairment predicted service use in all groups, but the association was of borderline significance. This is of concern and is contrary to what is reported in the literature on mental health service use in the general population, which has consistently suggested that the most unwell are the most likely to receive treatment. ${ }^{28,32}$

\section{Sources of help}

The percentage of personnel who are seeking help from medical sources is low, despite access to both primary and secondary care being easily available for those in the still-serving military, and bespoke services provided for reservists (The Reservists Mental 
Health Programme) ${ }^{33}$ and veterans (for example, by the charity Combat Stress). These findings are similar to those reported in general population studies, ${ }^{28,32,34}$ and also similar to the rates reported from the USA and Canada for active duty personnel. ${ }^{4,35,26}$ Hoge et al reported that only $27 \%$ of those returning from combat in Iraq with a diagnosis had seen a mental health professional. ${ }^{4}$ The rate of help-seeking from professionals for alcohol problems in comparison with depression and PTSD is especially low and has been reported previously in military populations. ${ }^{37}$

The general population literature has consistently demonstrated that, regardless of what services are made available, people prefer to seek help for mental disorders from social networks such as friends, family and the clergy ${ }^{38}$ rather than to consult a professional. ${ }^{27,39}$ This may be especially true in the 'macho' culture of the military where great emphasis is placed on resilience and self-sufficiency during training. Indeed such attributes are an asset and adaptive during deployment, but become problematic when maintained after homecoming.

The very real career implications of formal presentation with mental health problems while still serving also need the borne in mind and are likely to be a potent driver steering participants to non-professional sources of help. We know that mental health problems do have career implications for certain occupational roles within the military - for example, whether personnel are allowed to carry weapons, or pilot military aircraft. If service personnel do choose to consult their doctor, although confidentiality is a guiding principle, it cannot be absolute. The military chain of command may be informed if a member of their unit is suffering from a health problem, physical or mental, which is deemed to affect their employability. Although the health information that is passed on is general in nature and covers basic employability issues, rather than health details, this is still presumably a deterrent for personnel. We have previously shown that non-medical sources of help are preferable to peacekeepers returning with psychological difficulties. ${ }^{40}$ The implication of this for the military is that peer-led interventions such as Trauma Risk Management (TRiM) may be especially acceptable and useful. ${ }^{41}$ It also suggests that programmes designed to educate non-medical providers about the symptoms of common mental illness, and appropriate routes for referral may be fruitful. For example, it may be possible to train non-medical help providers such as clergy in simple interventions that can aid recovery as suggested by Schnell et al. ${ }^{42}$

For those who have left, it highlights the role that service charities play in helping veterans to maintain the cohesive social network they had in the military, and also to signpost those who are unwell and require treatment.

The majority of those seeking medical help for their mental disorder are dealt with in primary care; the same is true in the general population. ${ }^{32}$ The general population literature suggests that the majority of the population prefer to be seen in primary care for a mental disorder, ${ }^{27,43,44}$ and GPs are considered by the general public to be skilled in the assessment and treatment of such conditions. ${ }^{28}$ The implications of this are that primary care providers are ideally placed to assess and begin treatment for common mental disorders seen in military personnel.

\section{Receipt of treatment}

Given that there are evidence-based effective treatments available for the disorders we identified in this occupational group (alcohol misuse, depressive disorders and PTSD), most individuals have the potential to return to normal levels of functioning with appropriate care. In this sample most respondents who were in receipt of treatment were receiving medication or talking treatments such as counselling (not CBT), despite CBT being a recognised first-line treatment for $\mathrm{PTSD}^{45}$ and moderate/severe depression. ${ }^{46}$ The low levels of personnel receiving evidence-based treatments for common mental disorders is a concern. A recent Improving Access to Psychological Therapies (IAPT) initiative that aims to make access to CBT within primary care settings swifter and easier for veterans is timely and relevant (www.iapt.nhs.uk/special-interests/veterans).

\section{Comparisons with other deployed forces}

Our results are comparable with rates of help-seeking reported in UK veterans of the 1991 Gulf War. Iversen et al reported that 58\% of those with a diagnosis on the Primary Care Evaluation of Mental Disorders (PRIME-MD) were currently seeking help for their problem. ${ }^{19}$ This suggests that despite the initiatives to facilitate help-seeking and to decrease the stigma of mental disorders implemented since $2003,{ }^{47}$ the percentage of people who seek help has not increased in the past 5 years. This is in contrast to US work that has demonstrated a significant increase in the percentage of returnees seeking mental healthcare after conflict in recent years, although this is almost certainly a sideeffect of screening, and has yet to be matched with evidence of improved outcomes. ${ }^{5,48}$ The reasons for the lack of change in the UK are complex but are in part the result of the glacial pace of behavioural and cultural change especially within large organisations. We also know that prior to the current 'Time to Change' programme (www.time-to-change.org.uk), anti-stigma interventions to date (whether they be military or civilian) have concentrated on awareness raising and attempts to change general attitudes towards mental illness, rather than being directly designed to change behaviour or promote help-seeking, and the evidence that knowledge or attitude interventions alone (or even in combination) change behaviour is weak. ${ }^{49}$

Our results are also comparable with those reported by Schell et al, in a large telephone-based survey of Iraq War returnees. ${ }^{42}$ The uniformity of unmet need across both countries, despite very different models of service delivery for veterans, suggests that the problem with help-seeking may be intrinsic to military personnel themselves, and not the services available. We explore barriers to care in a subsequent paper, but previous reports have identified stigma as the dominant reason for reticence in seeking care. ${ }^{4,42}$

\section{Comparisons with the general population}

Rates of help-seeking between the general population and our sample are broadly comparable. The recent Adult Psychiatric Morbidity Survey (APMS) conducted in England in $2007^{50}$ revealed that $22 \%$ of those screening positive for PTSD had some form of community care within the past year compared with $20 \%$ of regulars, $14 \%$ of reservists and $24 \%$ of veterans screening positive for PTSD in our study. In the APMS, $65 \%$ of those with a depressive disorder had spoken with their GP in the past year compared with $93 \%$ of regulars, $87 \%$ of reservists and $72 \%$ of veterans in our study (although in our study we cannot be sure they consulted for their mental health problems).

Rates of help-seeking reported here are also comparable with historical reports of the general population in the UK, ${ }^{51}$ Europe $^{52}$ and the USA general population. ${ }^{34}$ It is perhaps surprising that the military population is comparable with the general population in terms of their help-seeking behaviour, given that certain socioeconomic groups at risk of non-consulting are over-represented in the military (e.g. younger men, those from lower socioeconomic groups). However, as this is a group at high risk of 
occupational psychiatric injury, it could be argued that they should be even more prepared to seek help than the general population when they have symptoms, especially as mental health services can be easily and quickly accessed by those who are still serving.

In this sample, the overall rate of treatment for those in the still-serving population with mental disorders $(13 \%)$ is even lower than that reported in the general population $(26 \%$ received treatment in a European study, ${ }^{53} 33 \%$ received treatment in an American study). ${ }^{54}$

\section{Implications}

Rates of help-seeking from medical sources and receipt of treatment are low in this sample of UK armed forces personnel, especially for alcohol misuse and depression/anxiety. Instead, personnel indicate a clear preference to consult peers, friends and non-medical sources of help such as chaplains. These results are similar to those reported for military personnel in the USA, and to rates in the general population. It has often been assumed that the unmet burden of mental illness in the still-serving and veteran community is as a result of a paucity of appropriate services being available. This study indicates that the main reason that people do not access services is that they make a decision much earlier in the pathway to care that that they do not need help. Therefore, novel 'system level' interventions to improve service personnel's recognition of common mental disorders that require treatment, and reduce the stigma of consulting, are important areas for research and evaluation.

Amy C. Iversen, MRCPsych, Lauren van Staden, MA, King's Centre for Military Health Research, King's College London; Jamie Hacker Hughes, PsychD, Academic Centre for Defence Mental Health, King's College London; Tess Browne, BSC, King's Centre for Military Health Research, King's College London; Neil Greenberg, MD, Academic Centre for Defence Mental Health, King's College London. Matthew Hotopf, PhD, Roberto J. Rona, FFPH, Simon Wessely, FMedSci, King's Centre for Military Health Research, King's College London; Graham Thornicroft, PhD, Health Service and Population Research Department, King's College London; Nicola T. Fear DPhil (Oxon), Academic Centre for Defence Mental Health, King's College London

Correspondence: Amy C. Iversen, King's Centre for Military Health Research, King's College London, Weston Education Centre, Cutcombe Road, London SE5 9RJ, UK. Email: amy.c.iversen@kcl.ac.uk

First received 25 Nov 2009, final revision 6 Apr 2010, accepted 27 Apr 2010

\section{Funding}

This study was funded by the UK's Ministry of Defence contract number R\&T/1/0078. M.H G.T. and S.W. are partially funded by the South London and Maudsley NHS Foundation Trust/Institute of Psychiatry National Institute of Health Research Biomedical Research Centre.

\section{References}

1 Ministry of Defence. Operations in Afghanistan: British Fatalities. MOD, 2010 (http://www.mod.uk/Defencelnternet/FactSheets/OperationsFactsheets/ OperationsInAfghanistanBritishFatalities.htm).

2 Ministry of Defence. Operations in Iraq: British Fatalities. MOD, 2010 (http://www.mod.uk/Defencelnternet/FactSheets/OperationsFactsheets/ OperationsInIraqBritishFatalities.htm).

3 Jones E, Wessely S. Psychiatric battle casualties: an intra- and interwar comparison. Br J Psychiatry 2001; 178: 242-7.

4 Hoge CW, Castro CA, Messer SC, McGurk D, Cotting DI, Koffman RL. Comba duty in Iraq and Afghanistan, mental health problems, and barriers to care. N Engl J Med 2004; 351: 13-22.

5 Hoge CW, Auchterlonie JL, Milliken CS. Mental health problems, use of mental health services, and attrition from military service after returning from deployment to Iraq or Afghanistan. JAMA 2006; 295: 1023-32.
6 Hotopf M, Hull L, Fear NT, Browne T, Horn O, Iversen A, et al. The health of UK military personnel who deployed to the 2003 Iraq war: a cohort study. Lancet 2006; 367: 1731-41.

7 Hoge CW, Lesikar SE, Guevara R, Lange J, Brundage JF, Engel CC Jr, et al. Mental disorders among U.S. military personnel in the 1990s: association with high levels of health care utilization and early military attrition. Am J Psychiatry 2002; 159: 1576-83.

8 Fletcher M. Lonely death of Private Dave Forshaw: the Territorial soldier in turmoil. The Times 2007; 13 October (http://www.timesonline.co.uk/tol/ news/uk/article2648621.ece).

9 Mostrous A, Macintyre B. British solidiers victims of a mental conflict without end. The Times 2009; 28 March.

10 Iversen AC, van Staden L, Birtles C, Hacker Hughes J, Browne T, Langston V, et al. The prevalence of common mental disorders and PTSD in the UK military: data from a clinical interview-based study. BMC Psychiatry 2009; 9: 68

11 Goldberg D. The Detection of Psychiatric Illness by Questionnaire. Oxford University Press, 1972.

12 Spitzer RL, Kroenke K, Williams JB. Validation and utility of a self-report version of PRIME-MD: the PHQ primary care study. Primary Care Evaluation of Mental Disorders. Patient Health Questionnaire. JAMA 1999; 282: 1737-44.

13 Prins $A$, Kimerling $R$, Cameron $R$, Oumiette $P C$, Shaw J, Thraikill A. The Primary Care PTSD Screen (PC-PTSD). Proc Int Soc Traumatic Stress Stud 1999; 15: 100.

14 Chisholm D, Knapp MRJ, Knudsen HC, Amaddeo F, Gaite L, van Wijngaarden B. Client Socio-Demographic and Service Receipt Inventory - European Version: development of an instrument for international research. EPSILON Study 5. Br J Psychiatry 2000; 117 (suppl 39): s28-33.

15 Pinto-Meza A, Serrano-Blanco A, Penarrubia MT, Blanco E, Haro JM. Assessing depression in primary care with the PHQ-9: can it be carried out over the telephone? J Gen Intern Med 2005; 20: 738-42.

16 Milliken CS, Auchterlonie JL, Hoge CW. Longitudinal assessment of mental health problems among active and reserve component soldiers returning from the Iraq war. JAMA 2007; 298: 2141-8.

17 Kessler R, Somnnega A, Bromet E, Nelson C, Hughes M, Nelson C. Posttraumatic stress disorder in the National Comorbidity Survey. Arch Gen Psychiatry 1995; 52: 1048-60.

18 Tate AR, Jones M, Hull L, Fear NT, Rona R, Wessely S, et al. How many mailouts? Could attempts to increase the response rate in the Iraq war cohort study be counterproductive? BMC Med Res Methodol 2007; 7: 51.

19 Iversen A, Dyson C, Smith N, Greenberg N, Walwyn R, Unwin C, et al. 'Goodbye and good luck': the mental health needs and treatment experiences of British ex-service personnel. Br J Psychiatry 2005; 186 480-6.

20 Rona RJ, Hyams KC, Wessely S. Screening for psychological illness in military personnel. JAMA 2005; 293: 1257-60.

21 Gilbody S, Sheldon T, House A. Screening and case-finding instruments for depression: a meta-analysis. Can Med Assoc J 2008; 178: 997-1003.

22 Rona RJ, Jones M, Iversen A, Hull L, Greenberg N, Fear NT, et al. The impact of posttraumatic stress disorder on impairment in the UK military at the time of the Iraq war. J Psychiatr Res 2009; 43: 649-55.

23 Beebe TJ, McRae JA Jr, Barnes SA. A comparison of self-reported use of behavioral health services with Medicaid agency records in Minnesota. Psychiatr Serv 2006; 57: 1652-4.

24 Aquilino WS. Privacy effects on self-reported drug use: interactions with survey mode and respondent characteristics. NIDA Res Monogr 1997; 167 383-415.

25 Aquilino WS, Wright DL, Supple AJ. Response effects due to bystander presence in CASI and paper-and-pencil surveys of drug use and alcohol use. Subst Use Misuse 2000; 35: 845-67.

26 Rhodes AE, Lin E, Mustard CA. Self-reported use of mental health services versus administrative records: should we care? Int J Methods Psychiatr Res 2002; 11: 125-33.

27 Jorm AF, Korten AE, Jacomb PA, Christensen H, Rodgers B, Pollitt P. "Mental health literacy": a survey of the public's ability to recognise mental disorders and their beliefs about the effectiveness of treatment. Med J Aust 1997; 166: 182-6.

28 Verhaak PF, Prins MA, Spreeuwenberg P, Draisma S, van Balkom TJ, Bensing $\mathrm{JM}$, et al. Receiving treatment for common mental disorders. Gen Hosp Psychiatry 2009; 31: 46-55.

29 Wright A, Harris MG, Wiggers JH, Jorm AF, Cotton SM, Harrigan SM, et al. Recognition of depression and psychosis by young Australians and their beliefs about treatment. Med J Aust 2005; 183: 18-23.

30 Barkow K, Heun R, Ustun TB, Berger M, Bermejo I, Gaebel W, et al. Identification of somatic and anxiety symptoms which contribute to the 
detection of depression in primary health care. Eur Psychiatry 2004; 19: 250-7.

31 Regier DA, Hirschfeld RM, Goodwin FK, Burke JD Jr, Lazar JB, Judd LL. The NIMH Depression Awareness, Recognition, and Treatment Program: structure, aims, and scientific basis. Am J Psychiatry 1988; 145: 1351-7.

32 McManus $\mathrm{S}$, Meltzer $\mathrm{H}$, Brugha $\mathrm{T}$, Bebbington $\mathrm{P}$, Jenkins $\mathrm{R}$, and the Department of Health Sciences University of Leicester. Adult Psychiatric Morbidity in England, 2007: Results of a Household Survey. A Survey carried out for The NHS Information Centre for Health and Social Care by the National Centre for Social Research and the Department of Health Sciences, University of Leicester. The Health \& Social Care Information Centre, Social Care Statistics, 2009 (http://www.ic.nhs.uk/webfiles/publications/ mental\%20health/other\%20mental\%20health\%20publications/Adult\%20 psychiatric\%20morbidity\%2007/APMS\%2007\%20(FINAL)\%20Standard.pdf).

33. Ministry of Defence. Reserves' Mental Health Programme. MOD, 2010 (http://www.army.mod.uk/welfare-support/family/17051.aspx).

34 Wang PS, Lane M, Olfson M, Pincus HA, Wells KB, Kessler RC. Twelve-month use of mental health services in the United States: results from the National Comorbidity Survey Replication. Arch Gen Psychiatry 2005; 62: 629-40.

35 Fikretoglu D, Guay S, Pedlar D, Brunet A. Twelve month use of mental health services in a nationally representative, active military sample. Med Care 2008; 46: 217-23.

36 Fikretoglu D, Brunet A, Schmitz N, Guay S, Pedlar D. Posttraumatic stress disorder and treatment seeking in a nationally representative Canadian military sample. J Trauma Stress 2006; 19: 847-58.

37 Erbes C, Westermeyer J, Engdahl B, Johnsen E. Post-traumatic stress disorder and service utilization in a sample of service members from Iraq and Afghanistan. Mil Med 2007; 172: 359-63.

38 Wang PS, Berglund PA, Kessler RC. Patterns and correlates of contacting clergy for mental disorders in the United States. Health Serv Res 2003; 38: 647-73.

39 Parker GB, Brown LB. Coping behaviors that mediate between life events and depression. Arch Gen Psychiatry 1982; 39: 1386-91.

40 Greenberg N, Maingay S, Iversen A, Wessely S. Do military peacekeepers want to talk about their experiences? Perceived psychological support of UK military peacekeepers on return from their deployment. J Ment Health 2003; 12: $565-73$.

41 Greenberg N, Langston V, Jones N. Trauma risk management (TRiM) in the UK Armed Forces. J R Army Med Corps 2008; 154: 124-7.
42 Schell TL, Marshall GN. Survey of individuals previously deployed for OEF/OIF. In Invisible Wounds of War: Psychological and Cognitive Injuries, their Consequences, and Services to Assist Recovery (eds T Tanielian, L Jaycox). RAND Centre for Military Health Policy Research, 2008.

43 Priest RG, Vize C, Roberts A, Roberts M, Tylee A. Lay people's attitudes to treatment of depression: results of opinion poll for Defeat Depression Campaign just before its launch. BMJ 1996; 313: 858-9.

44 Wolff G, Pathare S, Craig T, Leff J. Community attitudes to mental illness. Br J Psychiatry 1996; 168: 183-90.

45 National Collaborating Centre for Mental Health. Post-Traumatic Stress Disorder: The Management of PTSD in Adults and Children in Primary and Secondary Care. Gaskell and the British Psychological Society, 2005 (http:// guidance.nice.org.uk/CG26/Guidance/pdf/English).

46 National Collaborating Centre for Mental Health. Depression: Management of Depression in Primary and Secondary Care. British Psychological Society and Gaskell, 2004 (http://www.nice.org.uk/CG023).

47 Gould M, Greenberg N, Hetherton J. Stigma and the military: evaluation of a PTSD psychoeducational program. J Trauma Stress 2007; 20: 505-15.

48 Rosenheck RA, Fontana AF. Recent trends In VA treatment of post-traumatic stress disorder and other mental disorders. Health Aff (Millwood) 2007; 26: 1720-7.

49 National Institute for Health and Clinical Excellence. Behavioural Change at Population, Community and Individual Levels. NICE, 2007 (www.nice.org.uk/ $\mathrm{PH} 6)$.

50 Office for National Statistics. The Adult Psychiatric Morbidity Survey in England 2007 (http://www.ic.nhs.uk/pubs/psychiatricmorbidity07).

51 Meltzer $H$, Bebbington $P$, Brugha $T$, Farrell M, Jenkins R, Lewis $G$. The reluctance to seek treatment for neurotic disorders. Int Rev Psychiatry 2003; 15: $123-8$.

52 Alonso J, Codony M, Kovess V, Angermeyer MC, Katz SJ, Haro JM et al. Population level of unmet need for mental healthcare in Europe. Br J Psychiatry 2007; 190: 299-306.

53 Wittchen HU, Jacobi F. Size and burden of mental disorders in Europe - a critical review and appraisal of 27 studies. Eur Neuropsychopharmacol 2005; 15: $357-76$.

54 Kessler RC, Demler O, Frank RG, Olfson M, Pincus HA, Walters EE, et al. Prevalence and treatment of mental disorders, 1990 to 2003. N Engl J Med 2005; 352: 2515-23. 